\title{
Gripe A (H1N1): segundo acto
}

\section{Influenza A (H1N1): act two}

\author{
Ò. Miró ${ }^{1,2}$, A. Trilla ${ }^{3}$
}

La gripe, un clásico de la medicina interpretado desde tiempos inmemoriales en todos los escenarios del mundo, se reestrenó de nuevo en España en abril de 2009¹ . Esta nueva versión, titulada para esta ocasión A (H1N1), había sido repuesta (¿de forma inesperada?) unas semanas antes en México ${ }^{2}$. Como en los clásicos de los grandes dramaturgos como William Shakespeare, Lope de Vega o Àngel Guimerà, la esencia de los protagonistas es casi siempre la misma y el desarrollo de la obra sigue un formato perfectamente definido en tres actos: planteamiento, desarrollo y desenlace.

Así, en el primer acto, que se inició en el verano de 2009, fueron presentados todos los intervinientes sin excepción: el protagonista, el virus, bien identificado y caracterizado molecularmente, pero cuyo comportamiento resultaba en este punto impredecible ${ }^{3,4}$; los pacientes, que iban a vivir una maldad aparentemente incrementada del virus; los epidemiólogos y microbiólogos, en quienes recaía el desarrollo táctico de la defensa ${ }^{6,7}$; los médicos asistenciales de diferentes especialidades, un ejército bregado en cientos de batallas, pero a pesar de ello temeroso de caer en la contienda ${ }^{8}$; y los responsables de la política sanitaria, moviéndose en un escenario de elevada incertidumbre inicial que no conseguía poner freno al pánico creciente de la población y a la presión de los medios de comunicación ${ }^{9}$. Este primer acto también incluyó todos los cuadros posibles: asistencia primaria ${ }^{10}$; servicios de urgencias $^{11-13}$, unidades de hospitalización convencional ${ }^{14}$ y unidades de cuidados intensivos (UCI) ${ }^{15}$. A pesar de ser un clásico, y de que todo tenía un tinte de deja $v u^{16}$, los ensayos previos habían sido pocos (si acaso el de unos años antes a raíz de la gripe aviar A $\left.(\mathrm{H} 5 \mathrm{~N} 1)^{17,18}\right)$ y por ello, en el debut, no faltaron los clásicos nervios. En la literatura ha quedado abundantísima documentación (7.342 documentos al escribir el descriptor "influenza A (H1N1)" en PubMed a 30 de enero de 2011) que testimonian lo sucedido durante los meses en los que transcurrió la acción: un calendario distinto, con un pico de actividad gripal en oc-

1. Área de Urgencias. Hospital Clínic. Barcelona.

2. Grupo de Investigación: "Urgencias: procesos y patologías", IDIBAPS, Barcelona.

3. Unidad de Epidemiologia, Evaluación y Soporte a la Investigación. Hospital Clínic. Barcelona.

\section{Correspondencia}

Dr. Òscar Miró

Hospital Clínic. Àrea d'Urgències

Villarroel, 170

08036 Barcelona

E-mail: omiro@clinic.ub.es 
tubre y noviembre de 2009 y cese de la actividad en enero de 2010, una elevada tasa de ataque, especialmente entre los niños de menos de 14 años (se alcanzaron tasas de 600 casos de síndrome gripal por 100.000 habitantes en este grupo de edad), una enfermedad relativamente benigna para la gran mayoría de pacientes pero, para un 1-3\% de ellos, una enfermedad con complicaciones y con algunos casos realmente graves y mortales, generalmente por desarrollo de una neumonía viral extensa y rápidamente evolutiva. La mortalidad se centró además en grupos de edad más jóvenes que en representaciones anteriores (edad media alrededor de 50 años). La vacuna llegó, pero llegó tarde, ya en la fase de descenso de la epidemia. Globalmente, este primer acto se saldó con una buena nota en España (e incluso los protagonistas recibieron algunos aplausos) como recientemente plasmaba, entre otros muchos artículos ${ }^{19-21}$, uno de Castilla y colaboradores aparecido en estas mismas páginas de Anales del Sistema Sanitario de Navarra ${ }^{22}$.

El segundo acto, inconcluso en el momento de escribir este editorial, arranca en diciembre de 2010, fecha en la que se volvió a alcanzar el criterio de epidemia (más de 100 casos por 100.000 habitantes). Hay que decir que a tenor de lo vivido en la presentación de la trama, el desarrollo se presumía interesante. Pero uno tiene la sensación que llegados a este punto intermedio de la obra, la intensidad narrativa parece haber disminuido de forma importante. Esta segunda ola de gripe A (H1N1) está siguiendo el calendario habitual de la gripe estacional, con una curva epidémica similar a la de la temporada 2008-2009 y en cualquier caso con un volumen de afectación inferior al que el primer acto nos hizo prever. Como era de esperar, el virus predominante en España, como en toda la Unión Europea, está siendo el virus pandémico A (H1N1) 2009 (que ha desplazado al virus A (H1N1) 1977 que era el que circulaba hasta ahora), con algunos aislamientos de virus B y también algunos de virus A (H3N2). El virus sigue afectando hasta ahora de forma mayoritariamente a los niños menores de 14 años y es uniformemente sensible a oseltamivir. El número de casos graves ha sido moderado y se han concentrado en las 2-3 primeras semanas de enero: se trata de pacientes "jóvenes" (edad media 50-60 años), con factores de riesgo (básicamente enfermedad pulmonar, enfermedad con inmunosupresión, obesidad mórbida, embarazo) en el $80 \%$ de casos y de los que el $30-40 \%$ han precisado ingreso en una unidad de cuidados intensivos (datos preliminares). Quizá parte del descenso de la carga dramática en este segundo acto se deba a que estas tres cepas aisladas hasta ahora son las que se han incluido en la vacuna estacional ofrecida, como cada año, al $20 \%$ de la población española (concentrada en la población de más de 60 años y en los grupos de riesgo) durante los meses otoñales de 2010. En este sentido, la tasa de cobertura de la vacunación $2010-2011$ se estima que ha sido del 70-80\% de la población de riesgo (es decir, se habrá vacunado un $16 \%$ de toda la población), hecho que añadido a los casos con inmunidad natural (infectados durante el año 2009-2010 o pacientes mayores de 65 años -un 30\% de los cuales presentan anticuerpos protectores-) o inducida por la vacuna pandémica del año 2009 (que en realidad fueron muy pocos, un 16-20\% de la población de riesgo, por lo que esta protección alcanzó solo al $4 \%$ de la población general) hace prever una menor incidencia de gripe esta temporada de la estimada a priori. Con todo, el personal sanitario 
continúa registrando tasas muy bajas de vacunación, que se sitúan en torno al $25 \%$. Sea como fuere, se percibe una cierta indiferencia entre el público, aunque no queda claro si se debe a la ausencia de noticias (en este caso, son buenas noticias) o a una "normalidad gripal recuperada" tras la situación inusual vivida el año 2009.

Probablemente, esta obra tendrá un tercer acto, que como no podría ser de otro modo, narrará la victoria de David contra Goliat, de la Medicina sobre la Enfermedad. Público y actores guardarán para sí recuerdos, pero sobre todo deben incorporar enseñanzas: la gripe es realmente imprevisible, necesitamos mejores sistemas de vigilancia epidemiológica en animales y en seres humanos, debe fomentarse la investigación desde todos los frentes y las ópticas posibles ${ }^{23,24}$, hay que mejorar nuestra capacidad de predicción, debemos distinguir claramente los escenarios posibles de los probables, es perentorio mejorar la capacidad de respuesta asistencial ${ }^{25}$, debemos intensificar la búsqueda de vacunas más rápidas y efectivas durante más tiempo o frente a distintos virus a la vez $\mathrm{y}$, especialmente, hay que aprender a comunicar mejor las situaciones de incertidumbre, en un mundo globalizado y ávido de información, donde ésta viaja de forma instantánea por medios clásicos pero también por redes sociales. Estas (y otras) lecciones sin duda han de servirnos en el futuro, cuando una nueva variación antigénica del virus de la gripe decida que ya es hora de volver a interpretar la obra.

\section{BIBLIOGRAFÍA}

1. Miró O, Rovira E, Blanco AJ, Salmerón JM, Gatell JM, Cervera C et al. Descripción clínica y epidemiológica de los primeros casos de la gripe nueva A (H1N1) atendidos en España. Emergencias 2009; 21: 166-171.

2. Saldaña díaz O, Carreón Méndez CA, Díaz Soto E. Epidemia de gripe nueva A (H1N1): La visión desde un servicio de urgencias de México DF. Emergencias 2009; 21: 224-227.

3. Novel Swine-Origin Influenza A (H1N1) Virus Investigation Team. Emergence of a Novel Swine-Origin Influenza A (H1N1) Virus in Humans. N Engl J Med 2009; 360: 2605-2615.

4. Torres-Lana A. Gripe humana y gripes animales: una convivencia forzada. Emergencias 2009; 21: 203-212.

5. Perez-Padilla R, de la Rosa-Zamboni D, Ponce de Leon S, Hernandez M, Quiñones-FalCONI F, BAutista E, et al. Pneumonia and respiratory failure from swine-origin influenza A (H1N1) in Mexico. N Engl J Med 2009; 361:680-689.

6. Vilella A, Trilla A. Gripe A (H1N1): Una nueva epidemia. Med Clin (Barc) 2009; 132:783-784.

7. Castro Delgado R, Arcos González P, Rodríguez Soler A. Sistema sanitario y triaje ante una pandemia de gripe: un enfoque desde la salud pública. Emergencias 2009; 21: 376-381.

8. Llorens P, Sánchez-Payá J, Martínez H, Portilla J, Martínez E, San Inocencio D et al. Infección por gripe nueva A (H1N1) en personal sanitario de un hospital terciario. Emergencias 2009; 21: 346-349.

9. Cohen J, Enserink M. Swine Flu. After delays, who agrees: the 2009 pandemic has begun. Science 2009; 324:1496-1497.

10. Fernández Girón M, Rodríguez Monje MT, Sánchez Salvador J, González Martínez L, Serrano GonzÁlez D. En los albores de una pandemia. Descripción del brote de gripe A atendido en un centro de salud de Leganés, Madrid, durante los meses de mayo a julio de 2009. Aten Primaria 2010; 42: 581-583. 
11. Miró O. Una nueva gripe en un viejo escenario. Emergencias 2009; 21: 321322.

12. González del Castillo J. La gripe nueva A (H1N1): papel de los servicios de urgencias como atalaya y primera línea de choque frente a brotes epidémicos. Emergencias 2009; 21: 162-163.

13. Boqué MC, Rello J. Puntos clave para la orientación y manejo terapéutico de los casos graves de gripe A (H1N1)v en urgencias. Emergencias 2009; 21: 370-375.

14. Cilla G, Pérez-Trallero E. Pandemia de influenza A (H1N1) 2009, 6 meses de experiencia. Med Clin (Barc) 2010; 135: 21-22.

15. Rodríguez A, Socías L, Guerrero Je, Figueira JC, González N, Maraví-Poma E et al. Pandemic influenza A in the ICU: experience in Spain and Latin America. Med Intensiva 2010; 34: 87-94.

16. Castilla J. Incidencia de la gripe y efectividad de la vacuna antigripal en la temporada 2004-2005. An Sist Sanit Navar 2006; 29: 97-106.

17. Hien TT, Liem NT, Dung NT, San LT, Mai PP, van Vinh Chau N et al. Avian influenza A (H5N1) in 10 patients in Vietnam. N Engl J Med 2004; 350: 1179-1188.

18. BaRRICARTE A. Gripe aviar. ¿La pandemia que viene? An Sist Sanit Navar 2006; 29: 7-12.

19. López-García E, Fernández-Arribas S, Pérez-Rubio A, Eiros-Bouza JM, CastrodezaSANZ JJ. Grupo de vigilancia de Castilla y León. Influenza (H1N1) 2009 in Castilla y Leon, Spain: hospitalized case studies and match with the protocols of action developed. Rev Esp Salud Pública. 2010; 84: 671-678.

20. Mayoral Cortés JM, Ruz Fernández J, Pachón Díaz J, Navarro Marí JM, Puell Gómez L, Pérez Morilla E et al. Infection by the pandemic virus (H1N1) 2009 in Andalusia. Rev Esp Salud Pública 2010; 84: 517-528.

21. Álvarez Rodríguez V, Merlo Loranca M, Cuesta Torices MM, Ruiz Polaina MJ, Martín Martínez A, Silvio J et al. Análisis del impacto y manejo de la pandemia de gripe A H1N1 en el servicio de urgencias de un hospital terciario. Emergencias 2010; 22: 181-186.

22. Castilla J, Morán J, Fernández-Alonso M, Martínez-Artola V, Zamora MJ, Mazón A et al. Caracterización de la pandemia de gripe A H1N1 2009 en Navarra. An Sist Sanit Navar 2010; 33: 287-296.

23. Miró O, Salgado E, González-Duque A, Tomás S, Burillo-Putze G, Sánchez M. Producción científica de los urgenciólogos españoles durante los últimos 30 años (1975-2004). Análisis comparativo con la actividad de otras especialidades en España y con la de urgenciólogos de otros países. Emergencias 2007; 19: 59-64.

24. Etxeberria J, Floristán Y, Ardanaz E, López-Escudero R, Castilla J. Análisis de la mortalidad semanal como herramienta para la detección temprana de alertas en salud pública. An Sist Sanit Navar 2010; 33: 167-178.

25. Dierssen-Sotos T, Rodríguez-Cundín P, Robles-García M, Gómez-Acebo I, Brugos-LlaMAZARES V, Llorca Díaz J. Factores que determinan la satisfacción del usuario con la asistencia hospitalaria. An Sist Sanit Navar 2009; 32: 317-325. 